\title{
Comparative experimental investigation and gap flow simulation in electrical discharge drilling using new electrode geometry
}

\author{
Ali Tolga Bozdana ${ }^{1}$ and Nazar Kais Al-Karkhi ${ }^{2}$ \\ ${ }^{1}$ Associate Professor, Mechanical Engineering Department, University of Gaziantep, Gaziantep, Turkey \\ ${ }^{2}$ Lecturer, Automated Manufacturing Engineering, University of Baghdad, Baghdad, Iraq \\ Correspondence to: Ali Tolga Bozdana (bozdana@gantep.edu.tr)
}

Received: 6 May 2017 - Revised: 18 August 2017 - Accepted: 21 August 2017 - Published: 20 September 2017

\begin{abstract}
This study presents experimental and numerical investigation on the effectiveness of electrode geometry on flushing and debris removal in Electrical Discharge Drilling (EDD) process. A new electrode geometry, namely side-cut electrode, was designed and manufactured based on circular electrode geometry. Several drilling operations were performed on stainless steel 304 using rotary tubular electrodes with circular and side-cut geometries. Drilling performance was characterized by Material Removal Rate (MRR), Electrode Wear Rate (EWR), and Tool Wear Ratio (TWR). Dimensional features and surface quality of drilled holes were evaluated based on Overcut (OC), Hole Depth (HD), and Surface Roughness (SR). Three-dimensional three-phase CFD models were built using ANSYS FLUENT software to simulate the flow field at interelectrode gap. Results revealed that the overall performance of side-cut electrode was superior due to improved erosion rates and flushing capabilities, resulting in production of deep holes with good dimensional accuracy and surface quality.
\end{abstract}

\section{Introduction}

Electrical Discharge Drilling (EDD) is an electro-thermal process used for drilling small holes on electrically conductive materials. It is based on the eroding effect of electric sparks occurring between tool electrode and workpiece (Bozdana and Ulutas, 2016). Drilling operations are conducted by tubular electrodes through which the dielectric fluid is flowing for washing the debris away from the machining zone. Adequate flushing at interelectrode gap is of significant importance in drilling of holes with high aspect ratios. In production of deep holes, proper circulation of dielectric and effective debris removal are difficult to achieve, which directly affect drilling performance and hole features.

Numerous methods have been contrived in order to improve flushing in EDD applications. Some researchers tried to manipulate the relative movement between electrode and workpiece to stimulate the removal of debris away from machining zone. Orbital movement of tool electrode in radial direction was employed for manipulating side interelectrode gap (Yu et al., 2009; Bamberg and Heamawatanachai, 2009).
Bottom interelectrode gap was also manipulated by applying ultrasonic vibrations in vertical direction (Yu et al., 2009; Jahan et al., 2012; Shabgard and Alenabi, 2015). Moreover, it is reported in literature that increasing electrode rotation (Yahagi et al., 2012; Yadav and Yadava, 2015; Dwivedi and Choudhury, 2016) and dielectric pressure (Munz et al., 2013; Selvarajan et al., 2015, 2016) provided improvements in flushing and machining performance. On the other hand, only few studies were conducted for investigating the effect of electrode shape in EDD process. Nastasi and Koshy (2014) added geometric features of helical and radial slots on cylindrical copper electrodes to improve gap flushing in drilling of 6061 aluminum alloy. Plaza et al. (2014) studied the effects of helix angle and flute depth on helical electrodes to improve debris removal when increasing the hole depth in drilling of Ti-6Al-4V. Another work on using helical electrode with use of ultrasonic vibrations applied on workpiece was conducted by Hung et al. (2006) in drilling of nickel alloy Hymu 80.

In addition to experimental investigations found in the literature, there are few studies on modeling the flow characteristics at electrode-workpiece interaction. Nastasi and Koshy 
Table 1. Chemical composition (in wt \%) of stainless steel 304.

\begin{tabular}{llll}
\hline C: $0.08(\max )$ & Mn: $2(\max )$ & Cr: $18-20$ & S: $0.03(\max )$ \\
N: 0.1 & Si: $0.75(\max )$ & Ni: $8-10.5$ & P: $0.045(\max )$ \\
\hline
\end{tabular}

(2014) modeled the flow fields in frontal and lateral gaps using ANSYS CFX to optimize tool electrode comprising geometric features. Xie et al. (2015a) presented 2-D flow model in ultrasonically assisted EDM process using Computational Fluid Dynamics (CFD). Their model involved phases of kerosene dielectric and debris at bottom and side regions of interelectrode gap. Wang and Han (2014a, b) proposed 3$\mathrm{D}$ model of flow field with liquid, gas, and solid phases to analyze the machining gap during electrode jump in EDM. The variations in bubble volume at interelectrode gap during ultrasonically assisted EDM were studied by Kong et al. (2015). 3-D geometrical modeling of flow field at interelectrode gap was established using FLUENT software. In the study of Xie et al. (2015b), 2-D model of flow field in ultrasonic assisted EDM was constructed with liquid and debris phases. Debris distribution and velocity variations at bottom and side gaps during ultrasonic vibration cycle were investigated through the numerical simulations. Zhang et al. (2015) developed 2-D model to simulate movement and distribution of the debris in EDM with self-adaptive electrode movement. The results indicated that the quantity of debris flushed away was limited and most of debris in the gap was aggregated at interelectrode gap.

This study presents experimental and numerical investigations on EDD of stainless steel 304 using circular and sidecut electrodes. Several drilling operations were performed in order to examine the effectiveness of electrode geometry on machining performance as well as dimensional accuracy and surface quality of drilled holes. Numerical analyses were carried out based on 3-D three-phase CFD models for simulation of flushing capabilities of electrodes.

\section{Experimental work}

Tubular brass electrodes with cylindrical and side-cut electrode geometries were used in this study. Circular electrode is commercially available, and side-cut electrode was manufactured by milling two sides of circular electrode (Fig. 1). Both electrodes have the identical inner and outer diameters of $\varnothing 1$ and $\varnothing 3 \mathrm{~mm}$, respectively. Therefore, it is possible to make reliable comparison between performance flushing and sparking characteristics of these electrodes.

Workpiece material was stainless steel 304 having chemical composition given in Table 1 . Holes were drilled on block specimens of $50 \times 35 \times 4 \mathrm{~mm}$, as illustrated in Fig. 2 . They were produced on mating interface of specimens. After drilling, specimens were separated to perform measurements on the surfaces of drilled holes.
Table 2. Drilling parameters.

\begin{tabular}{ll}
\hline Peak current & $24 \mathrm{~A}$ \\
Pulse-on time & $44 \mu \mathrm{s}$ \\
Pulse-off time & $5 \mu \mathrm{s}$ \\
Voltage & $50 \mathrm{~V}$ \\
Capacitance & $1476 \mu \mathrm{F}$ \\
Dielectric fluid & Deionized water \\
Dielectric pumping pressure & $30 \mathrm{~kg} \mathrm{~cm}^{-2}$ \\
Electrode rotation speed & $200 \mathrm{rpm}$ \\
\hline
\end{tabular}
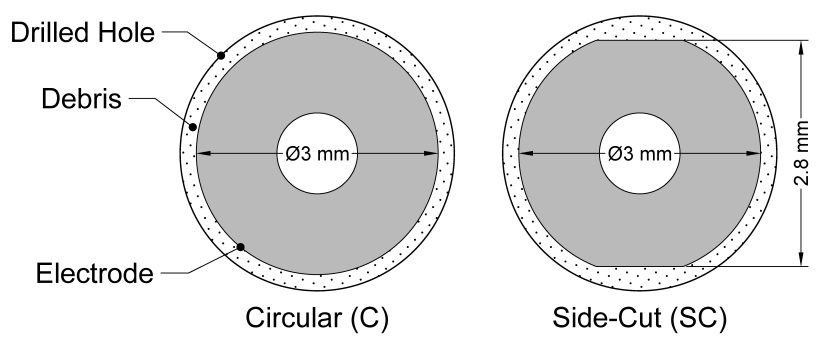

Figure 1. Circular and side-cut electrode geometries.

Table 2 presents the process parameters used in drilling operations. Five holes using both electrode geometries were drilled at five machining durations (namely 1, 2, 3, 4, and $5 \mathrm{~min}$ ). This was done to investigate the effectiveness of electrode geometries on drilling performance and hole characteristics at different hole depths.

Drilling operations were conducted on JS AD-20 hole drilling EDM machine (Fig. 3). Vertical movement of the electrode was achieved by servo control while axis movements were displayed on coordinate display. Machining settings were selected on the control panel. The dielectric fluid was filtered and pumped through hollow electrode during drilling process.

Process performance was evaluated based on Material Removal Rate (MRR) and Electrode Wear Rate (EWR) as given in Eqs. (1) and (2), respectively. The weights of specimens and electrodes were measured using a digital scale with a precision of $\pm 1 \mathrm{mg}$. Drilling time was recorded by a precision timer. In addition, Tool Wear Ratio (TWR) was employed in order to evaluate the dimensionless effect between electrode wear and material removal, as given in Eq. (3).

$$
\begin{aligned}
& \text { (specimen weight before drilling) } \\
& \operatorname{MRR}\left(\mathrm{g} \mathrm{min}^{-1}\right)=\frac{- \text { (specimen weight after drilling) }}{\text { drilling time }} \\
& \text { (electrode weight before drilling) } \\
& \operatorname{EWR}\left(\mathrm{g} \mathrm{min}^{-1}\right)=\frac{-(\text { electrode weight after drilling })}{\text { drilling time }}
\end{aligned}
$$



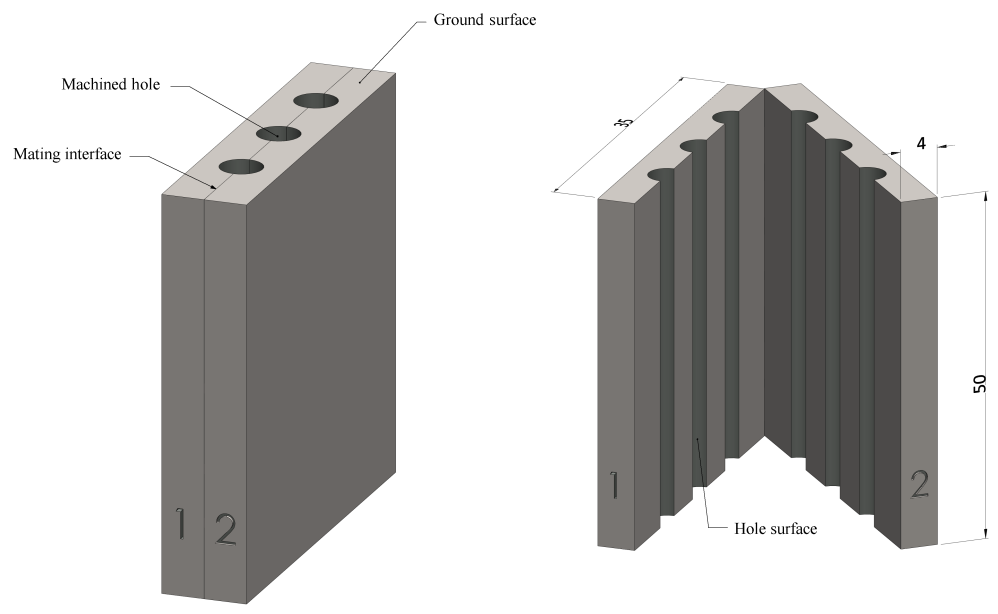

Figure 2. Sketch of specimens (all dimensions in $\mathrm{mm}$ ).

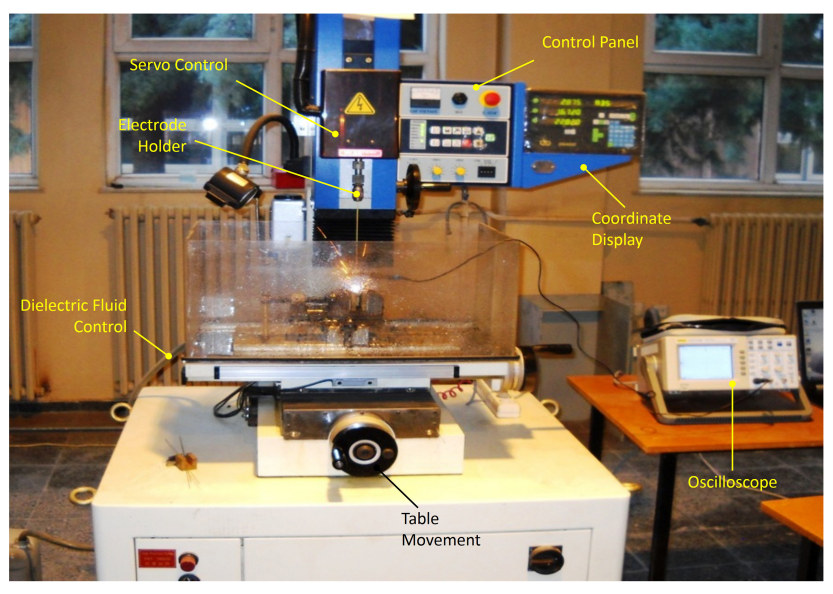

Figure 3. Hole drilling EDM machine with experimental setup.

$\mathrm{TWR}=\frac{\mathrm{EWR}}{\mathrm{MRR}}$

Diameter and depth of drilled holes were measured on photographs taken by high-resolution scanner. Due to sidesparking between electrode and workpiece, diameter of drilled hole is always larger than electrode diameter. This is called Overcut (OC), which was calculated based on the enlargement in hole diameter with respect to electrode diameter (Eq. 4).

$\mathrm{OC}(\%)=$

$\frac{\text { (measured hole diameter })- \text { (electrode diameter })}{\text { electrode diameter }} \times 100$

Surface quality of holes was evaluated based on Surface Roughness (SR). On each hole surface, the roughness average $\left(R_{\mathrm{a}}\right)$ was measured using Mitutoyo SJ-401 roughness tester with a cut-off length of $0.8 \mathrm{~mm}$. The measurements were repeated three times at different regions on each hole surface, and the average of readings was taken as the roughness value.

\section{Numerical analyses}

Flow characteristics were analyzed based on three-phase model of flushing (i.e. water as liquid phase, bubbles as gas phase, and debris as solid phase) in ANSYS FLUENT software. The interaction between bubbles and water was simulated with Euler-Euler VOF model (Xie et al., 2015a; Wang and Han, 2014a, b) by solving the volume continuity equation as follows (Kong et al., 2015):

$\frac{\partial}{\partial t}\left(\alpha_{\mathrm{g}} \rho_{\mathrm{g}}\right)+\nabla \cdot\left(\alpha_{\mathrm{g}} \rho_{\mathrm{g}} v_{\mathrm{g}}\right)=\sum_{L=1}^{n} m_{L \mathrm{~g}}$

where $\alpha_{\mathrm{g}}$ is the volume fraction of gas, $\rho_{\mathrm{g}}$ is the density of gas, $v_{\mathrm{g}}$ is the velocity of gas, $m_{L \mathrm{~g}}$ is the mass transfer from liquid phase to gas phase. The function DEFIEN_MASS_TRANSFER was used to describe the transfer of water into gas (Wang and Han, 2014a). When discharge occurs, the water starts being transferred into bubbles. Processing of the water volume fraction $\left(\alpha_{L}\right)$ was computed by the following equation (Kong et al., 2015):

$\alpha_{\mathrm{g}}+\alpha_{L}=1$.

For the VOF model, a single momentum conservation equation of the entire flow field was solved. The momentum equation was depending upon the volume fractions of all phases through $\rho$ and $\mu$ (Wang and Han, 2014a):

$$
\begin{aligned}
\frac{\partial}{\partial t}\left(\rho_{\mathrm{a}} v\right) & +\nabla \cdot\left(\rho_{\mathrm{a}} v v\right)=-\nabla p+\nabla \cdot\left[\mu_{\mathrm{a}}\left(\nabla v+\nabla v^{\mathrm{T}}\right)\right] \\
& +\rho_{\mathrm{a}} g+F
\end{aligned}
$$

where $\rho_{\mathrm{a}}$ and $\mu_{\mathrm{a}}$ were taken as the average of volume fraction values of all the phases, and $F$ denotes the external body 
forces (i.e. the forces from interaction with the dispersed phases). The calculations of $\rho_{\mathrm{a}}$ and $\mu_{\mathrm{a}}$ for two phases are as follows:

$\rho_{\mathrm{a}}=\alpha_{L} \rho_{L}+\alpha_{\mathrm{g}} \rho_{\mathrm{g}}$

$\mu_{\mathrm{a}}=\alpha_{L} \mu_{L}+\alpha_{\mathrm{g}} \mu_{\mathrm{g}}$

where $\alpha_{L}$ and $\alpha_{\mathrm{g}}$ are the volume fractions of liquid and gas phases, respectively.

The debris moves with dielectric fluid in the machining gap, and hence their movement is abided by a discrete phase particle by integrating the force balance on debris, which is written in a Lagrangian reference frame. The motion equation of debris in the gap flow can be determined by Newton's second law of motion (Wang and Han, 2014a):

$$
\frac{\mathrm{d} u_{\mathrm{p}}}{\mathrm{d} t}=\frac{g_{z}\left(\rho_{\mathrm{p}}-\rho_{L}\right)}{\rho_{\mathrm{p}}}+F_{z}+F_{\mathrm{D}}\left(u_{L}-u_{\mathrm{p}}\right)
$$

where $u_{L}$ and $u_{\mathrm{p}}$ are the velocities of water and debris in the direction of electrode movement, $\rho_{L}$ and $\rho_{\mathrm{p}}$ are the densities of water and debris, $g_{z}$ is the gravitational acceleration. The first term on the right side of Eq. (10) is the buoyancy of debris. The second term on the right side of Eq. (10) is an additional force (e.g. thermo-Phoresis force and brown force), also including forces on particles arising due to rotation of the reference frame. The third term on the right side of Eq. (10) is the drag force of debris, in which $F_{\mathrm{D}}$ was calculated as follows (Wang and Han, 2014a):

$F_{\mathrm{D}}=\frac{18 \mu}{\rho_{\mathrm{p}} d_{\mathrm{p}}^{2}} \frac{C_{\mathrm{D}} R e}{24}$

where $\mu$ is the molecular viscosity of fluid, $d_{\mathrm{p}}$ is the diameter of debris particles, $R e$ is Reynolds number, $C_{\mathrm{D}}$ is the coefficient of drag force.

The energy equation was also solved for the VOF model as below (Theory Guide, 2009):

$$
\frac{\partial}{\partial t}(\rho E)+\nabla \cdot(v(\rho E+p))=\nabla \cdot\left(k_{\mathrm{eff}} \nabla T\right)+S_{\mathrm{h}} .
$$

The VOF model treats energy $(E)$ and temperature $(T)$ as mass-averaged variables:

$$
E=\frac{\sum_{q=1}^{n} \alpha_{q} \rho_{q} E_{q}}{\sum_{q=1}^{n} \alpha_{q} \rho_{q}}
$$

where $E_{q}$ for each phase is based on the specific heat of that phase and the shared temperature. The properties of $\rho$ and $k_{\text {eff }}$ (effective thermal conductivity) are shared by phases. The source term $\left(S_{\mathrm{h}}\right)$ contains contributions from radiation as well as any other volumetric heat sources.
A three-dimensional model of the flow field during consecutive-pulse discharge was created. The deionized water (i.e. liquid phase) was introduced through the inner portion of hollow electrode. The air (i.e. the bubbles occurring due to vaporization) and the debris (i.e. the particles eroded from workpiece) were generated within the gap between electrode tip and workpiece. The model equations given in previous section were solved using a commercial CFD software package, FLUENT (v16.1). CFD simulations were done by means of GAMBIT tools in order to design the problem in geometrical configuration with appropriate mesh. Before solving fluid flow problems, FLUENT needs the domain, at which the flow takes place. Thereby, 3-D flow domains for both electrode geometries (i.e. circular and side-cut electrodes) were created in Solidworks ${ }^{\circledR}$. After that, a geometric model of the flow field domain inside the electrode and in the machining gap was divided into a certain number of cells (intervals) using GAMBIT software and imported into FLUENT. Solid models and the corresponding meshing for both electrode geometries are shown in Figs. 4 and 5, respectively.

In order to obtain a well-posed system of equations, reasonable boundary conditions for computational domain were implemented. The gap between electrode and workpiece was initially filled with liquid (i.e. deionized water). Air bubbles and debris started to occur at bottom region of electrode, resulting from the sparks generated at the tip of electrode, which melts the metal and boils the water. The outlet boundary condition was pressure that was set as $1.013 \times 10^{5} \mathrm{~Pa}$ (i.e. atmospheric pressure). Pressure boundary condition was applied at top of electrode with a static reference pressure of $30 \mathrm{~kg} \mathrm{~cm}^{-2}$. The inlet velocity was calculated as:

$\dot{m}=\rho u_{\mathrm{i}} A$

where $\dot{m}$ is the flow rate of water flowing through tubular electrode (measured as $0.001632 \mathrm{~kg} \mathrm{~s}^{-1}$ ), $\rho$ is the density of water (i.e. $998.2 \mathrm{~kg} \mathrm{~m}^{-3}$ ), and $A$ is the inner area of electrode $\left(0.785 \times 10^{-6} \mathrm{~m}^{3}\right)$. Thus, the inlet velocity $\left(u_{\mathrm{i}}\right)$ was about $2 \mathrm{~ms}^{-1}$. Wall boundary conditions were defined as no-slip condition for liquid phase whereas free-slip conditions for solid and gas phases. The electrode walls (side and bottom faces) were rotated at $200 \mathrm{rpm}$. The identical boundary conditions were applied for both electrodes geometries.

Simulations were carried out using FLUENT based on the experimental setup, as illustrated in Fig. 6. The maximum machining depth was $50 \mathrm{~mm}$. Side and bottom gaps were measured as suggested in literature (Wang and Han, 2014b). The difference between diameters of electrode and drilled hole was the dimension of side gap, and it was found to be about $100 \mu \mathrm{m}$. The dimension of bottom gap was determined based on the difference between vertical coordinates of electrode. The coordinate of electrode was recorded when spark occurred between electrode and workpiece. Without sparking, its coordinate was also recorded when electrode was in 


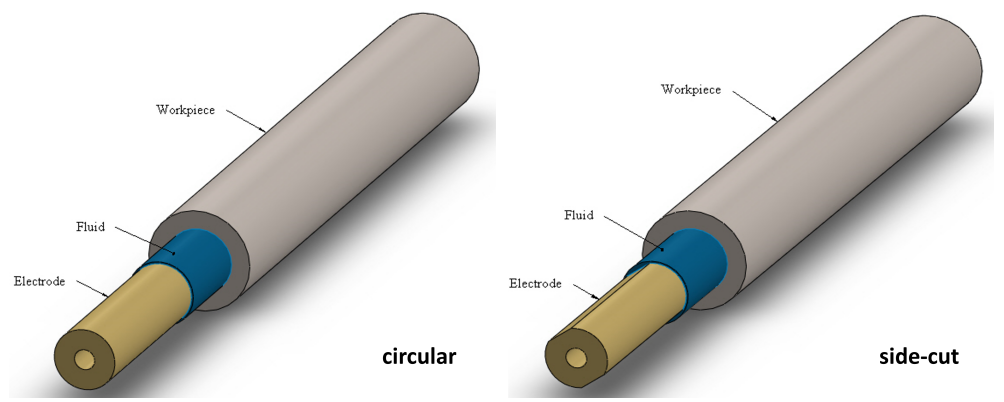

Figure 4. Solid models representing electrode-fluid-workpiece interaction.
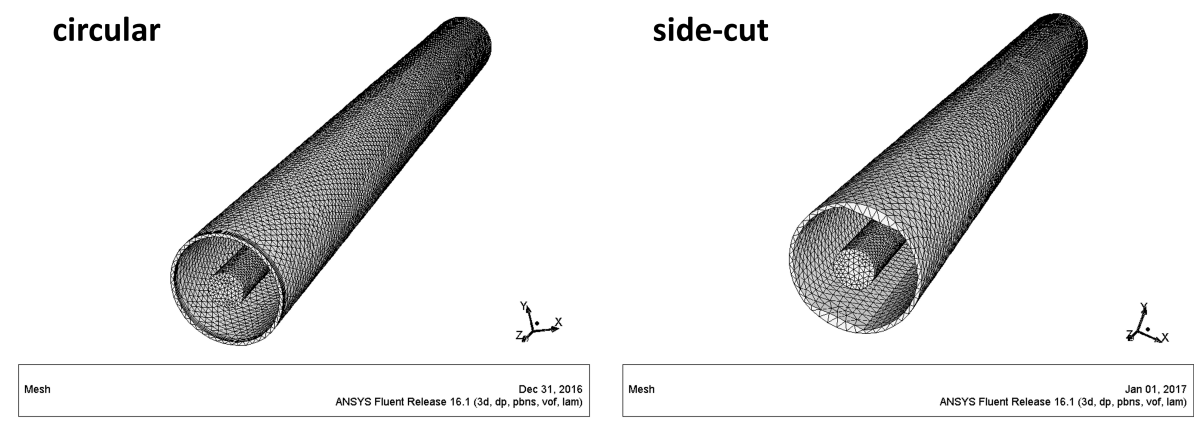

Figure 5. Meshed models representing the geometry at flushing gap.

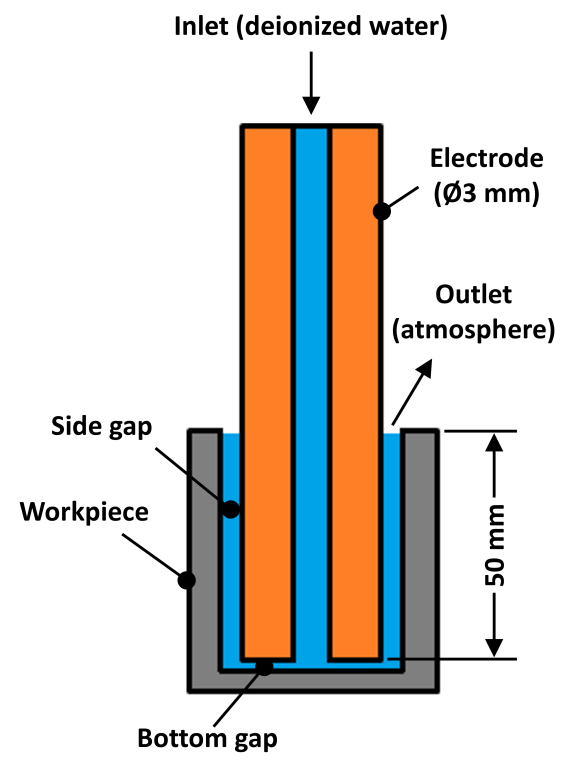

Table 3. The properties for liquid, solid, gas phases.

\begin{tabular}{lrrr}
\hline Property & $\begin{array}{r}\text { Liquid } \\
\text { (water) }\end{array}$ & $\begin{array}{r}\text { Solid } \\
\text { (stainless } \\
\text { steel 304) }\end{array}$ & $\begin{array}{r}\text { Gas } \\
\text { (air) }\end{array}$ \\
\hline Density $\left(\mathrm{kg} \mathrm{m}^{-3}\right)$ & 998.2 & 7000 & 1.225 \\
Conductivity $\left(\mathrm{W} \mathrm{m}^{-1} \mathrm{~K}^{-1}\right)$ & 0.6 & 17 & 0.0242 \\
Specific Heat $\left(\mathrm{J} \mathrm{kg}^{-1} \mathrm{~K}^{-1}\right)$ & 4182 & 530 & 1006.43 \\
Viscosity $\left(\mathrm{kg} \mathrm{m}^{-1} \mathrm{~s}^{-1}\right)$ & 0.001003 & - & $1.7894 \times 10^{-5}$ \\
\hline
\end{tabular}

was calculated with the following formula (Fang and Manglik, 2002):

$R e=\frac{\rho N r^{2}}{\mu}$

where $N$ is the angular velocity of rotating inner cylinder (rotational speed of electrode), $r$ is the outer radius of electrode. Therefore, the maximum Reynolds number of the side gap was calculated as 450 . This value is much smaller than the critical value of 2300. Thus, the flow inside the gap was said to be laminar. The properties for all phases are given in Table 3.

touch with workpiece. The difference between two coordinates of electrode was the dimension of bottom gap, which was determined as $480 \mu \mathrm{m}$.

In order to verify the flow type of flow field in the machining gap (i.e. laminar or turbulent flow), Reynolds number $(R e)$ of inner cylinder rotation with axial flow in annuli

\section{Results and discussion}

Five holes were drilled using circular and side-cut electrodes at drilling times of $1,2,3,4,5 \mathrm{~min}$, respectively. Figure 7 

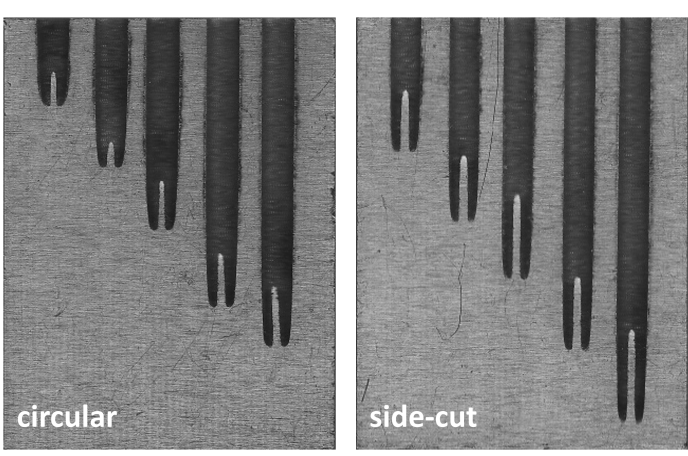

Figure 7. Photographs of drilled holes.

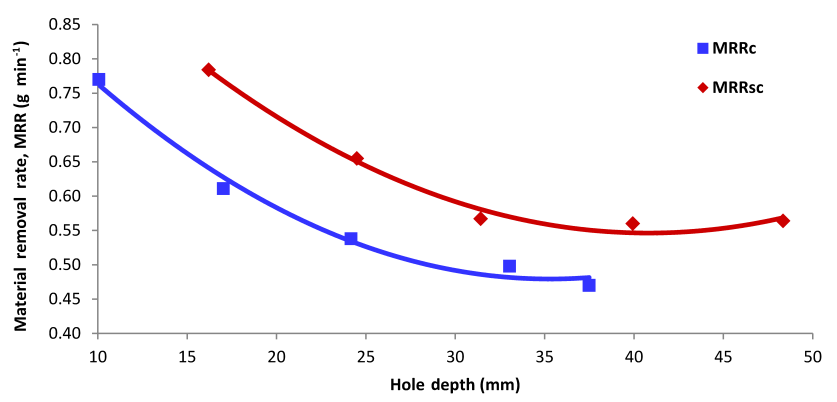

Figure 8. Results of MRR with respect to hole depth.

shows photographs of drilled holes. Table 4 presents results of MRR, EWR, TWR, OC, and SR obtained after drilling operations.

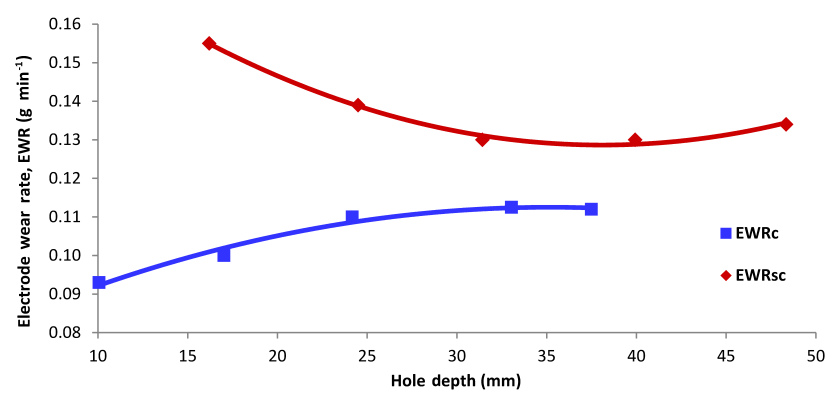

Figure 9. Results of EWR with respect to hole depth.

MRR is a significant factor in EDD process because of its vital influence on engineering economy. Higher MRR value refers to greater amount of material removal per unit time. Results of MRR for circular and side-cut electrodes are compared in Fig. 8. Side-cut electrode provides higher MRR values as compared with circular electrode, resulting in deeper holes. This is due to the reason that spark intensity was increased and flushing was improved in case of side-cut electrode. For the deepest hole, there is about $20 \%$ increase in MRR when side-cut electrode was used. It is also observed that MRR values for side-cut electrode are not diminished after specific hole depth whereas material removal by circular

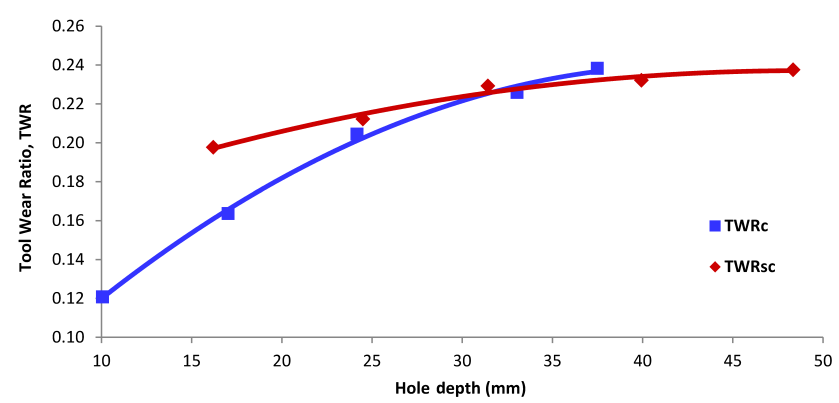

Figure 10. Results of TWR with respect to hole depth.

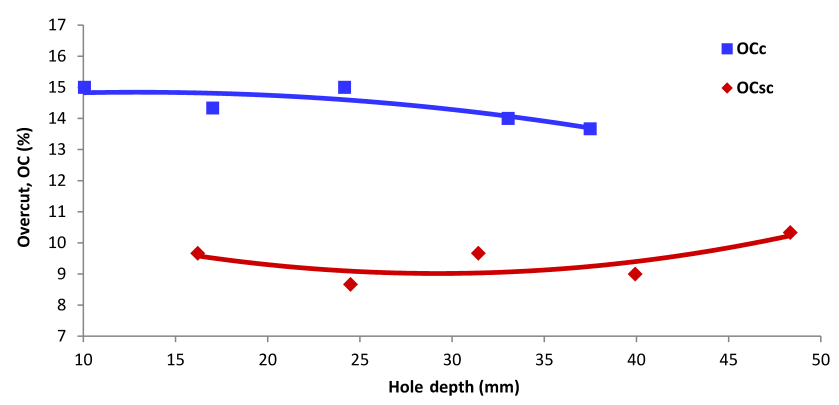

Figure 11. Results of OC with respect to hole depth.

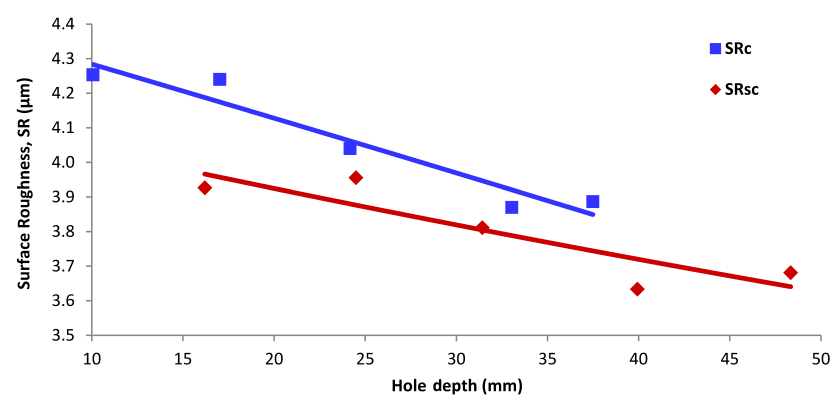

Figure 12. Results of SR with respect to hole depth.

electrode becomes lesser with increasing the depth. Moreover, MRR curves for both electrodes decrease with drilling depth since flushing the debris away from machining zone becomes more difficult.

EWR is also a significant parameter, which is related with MRR. Figure 9 shows EWR results for both electrodes. Sidecut electrode generally exhibits higher EWR, which is an expected case as the degree of erosion on both workpiece and electrode are proportional. Thus, providing high MRR, side-cut electrode causes high EWR. It is also observed that EWR for side-cut electrode decreases with an increase in hole depth while EWR for circular electrode increases due to weak flushing. This causes accumulation of debris in the machining zone, leading to increase in erosion on electrode.

TWR is usually employed as a parameter to evaluate the combined effect of MRR and EWR. It is desirable to have lower TWR value as it refers to lesser amount of electrode 


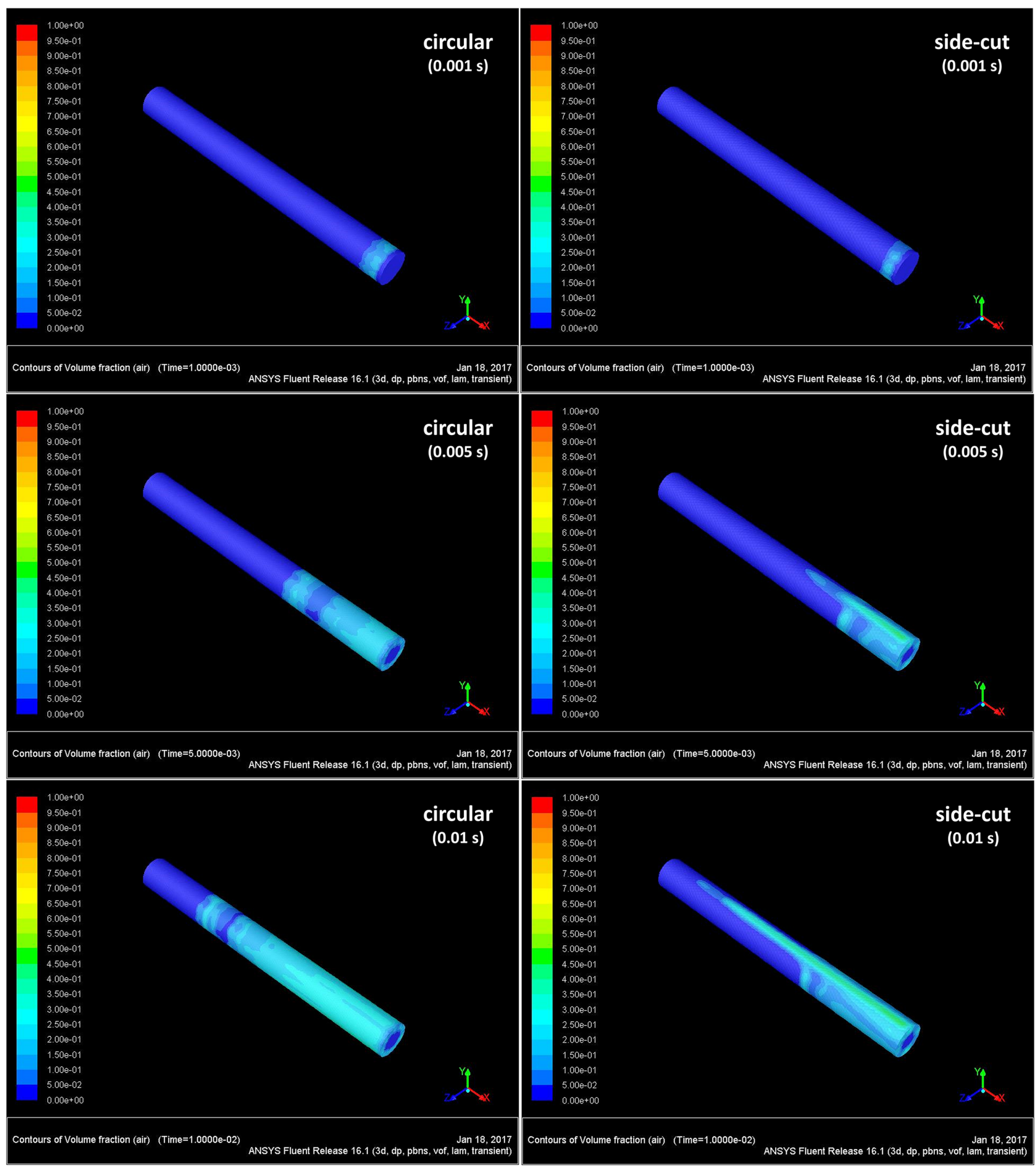

Figure 13. Volume fraction contours of bubbles at increasing time steps.

wear and greater material removal. As seen from Fig. 10, side-cut electrode causes moderate increase in TWR. However, in case of circular electrode, there is a significant increase in TWR.
Results of OC given in Fig. 11 reveal that side-cut electrode exhibits lower OC for all holes. This is due to the fact that circular electrode have greater contour along its perimeter for producing greater amount of side sparks, leading to 


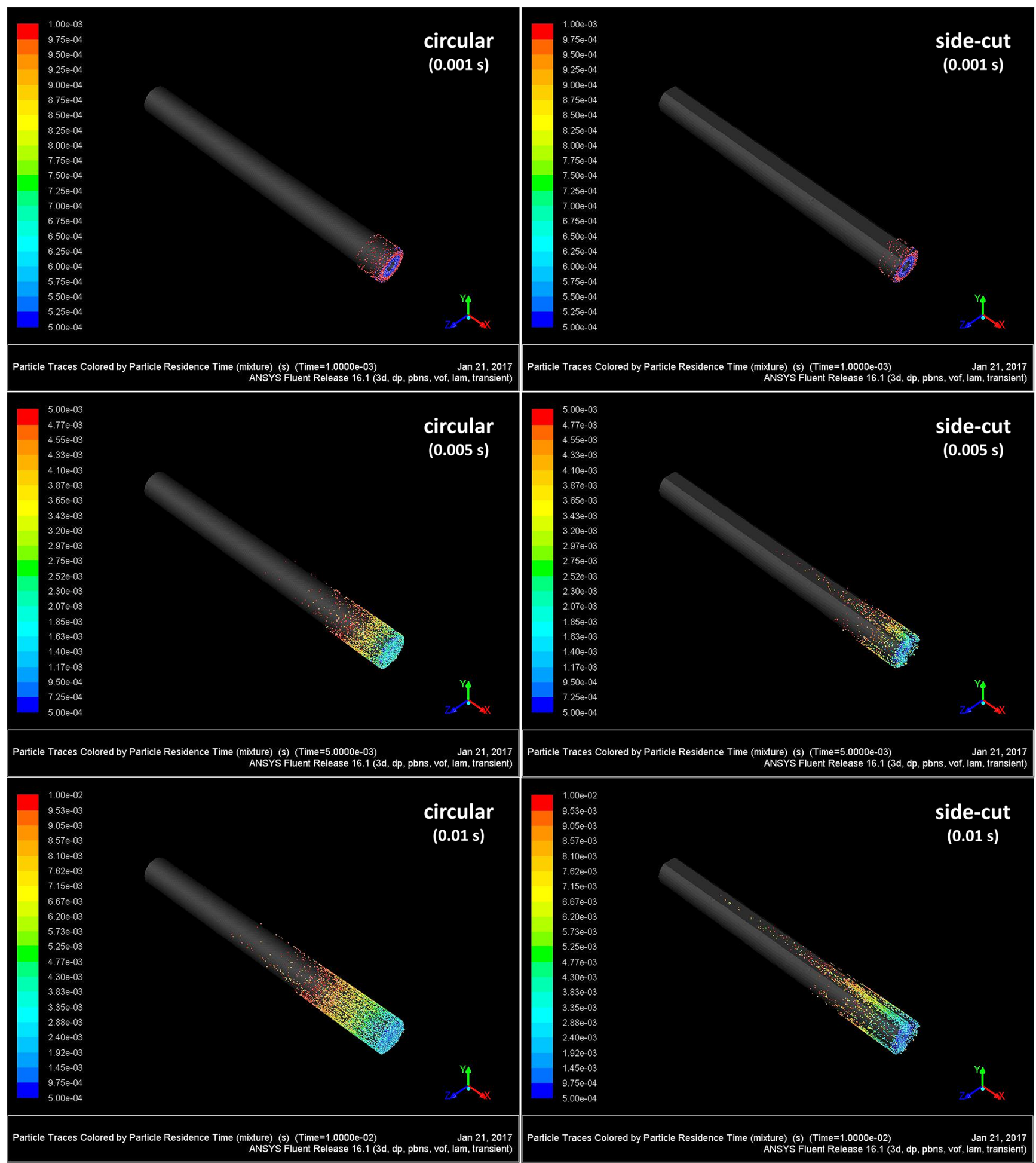

Figure 14. Debris distributions at increasing time steps.

higher degree of erosion, and hence larger enlargement in drilled hole diameter. On average, side-cut electrode provided an improvement of about $34 \%$ in OC over circular electrode.
The comparison for SR results is given in Fig. 12. Regardless of hole depth, side-cut electrode provides smoother hole surfaces. This is because of improved flushing capabilities of side-cut electrode so that the eroded particles can be effec- 
Table 4. Experimental results obtained by circular (C) and side-cut (SC) electrodes.

\begin{tabular}{|c|c|c|c|c|c|c|c|c|c|c|c|c|c|c|}
\hline \multirow{2}{*}{$\begin{array}{l}\text { Hole } \\
\text { No. }\end{array}$} & \multicolumn{2}{|c|}{ Dia. $(m m)$} & \multicolumn{2}{|c|}{ Depth (mm) } & \multicolumn{2}{|c|}{$\operatorname{MRR}\left(\mathrm{g} \mathrm{min}^{-1}\right)$} & \multicolumn{2}{|c|}{$\operatorname{EWR}\left(\mathrm{g} \mathrm{min}^{-1}\right)$} & \multicolumn{2}{|c|}{ TWR } & \multicolumn{2}{|c|}{$\mathrm{OC}(\%)$} & \multicolumn{2}{|c|}{$\mathrm{SR}(\mu \mathrm{m})$} \\
\hline & $\mathrm{C}$ & $\mathrm{SC}$ & $\mathrm{C}$ & $\mathrm{SC}$ & $\mathrm{C}$ & $\mathrm{SC}$ & $\mathrm{C}$ & $\mathrm{SC}$ & $\mathrm{C}$ & $\mathrm{SC}$ & $\mathrm{C}$ & SC & $\mathrm{C}$ & $\mathrm{SC}$ \\
\hline 1 & 3.45 & 3.29 & 10.06 & 16.20 & 0.770 & 0.784 & 0.093 & 0.155 & 0.121 & 0.198 & 15.00 & 9.67 & 4.25 & 3.93 \\
\hline 2 & 3.43 & 3.26 & 17.02 & 24.49 & 0.611 & 0.655 & 0.100 & 0.139 & 0.164 & 0.212 & 14.33 & 8.67 & 4.24 & 3.96 \\
\hline 3 & 3.45 & 3.29 & 24.17 & 31.42 & 0.538 & 0.567 & 0.110 & 0.130 & 0.204 & 0.229 & 15.00 & 9.67 & 4.04 & 3.81 \\
\hline 4 & 3.42 & 3.27 & 33.04 & 39.93 & 0.498 & 0.56 & 0.113 & 0.130 & 0.226 & 0.232 & 14.00 & 9.00 & 3.87 & 3.63 \\
\hline 5 & 3.41 & 3.31 & 37.49 & 48.34 & 0.470 & 0.564 & 0.112 & 0.134 & 0.238 & 0.238 & 13.67 & 10.33 & 3.89 & 3.68 \\
\hline
\end{tabular}

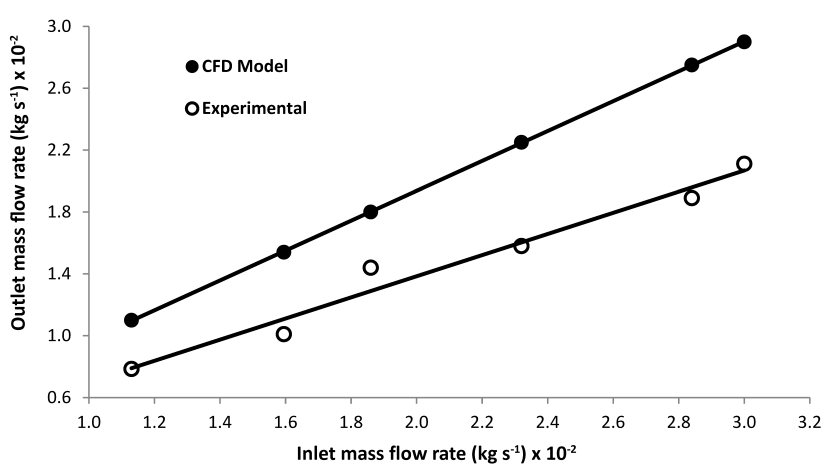

Figure 15. Validation of numerical model based on MFR.

tively washed away without sticking on workpiece surface, which results in hole surfaces free from resolidified debris.

Numerical simulations of inter-electrode gap were carried out to show the effectiveness of electrode shape on behavior of air bubbles as well as debris distribution at incremental time steps. Firstly, bubble distributions were simulated in order to define the motion of air bubbles from bottom gap to side gap. Figure 13 shows the simulation results of volume fraction at increasing time steps of $0.001,0.005$, and $0.01 \mathrm{~s}$. The left column of numerals with different color fringes correspond to the volume fraction of bubbles. For instance, the regions of blue color denoted by " 0 " are full of water. The results in Fig. 13 reveal that circular electrode exhibits uniformly distributed of areas of bubbles around the side gap. On the other hand, the bubble distribution is nonuniform in case of side-cut electrode, owing to its shape. The regions within the sides of cut provides extra space for the bubbles to flow, leading to stimulated motion of bubbles, which results in effective flushing capabilities.

Similar effects are observed for the debris distributions, as given in Fig. 14. The left column of numerals with different color fringes correspond to the accumulated moving time of debris. Regardless of the moving direction of debris and velocity field, the dispersion degree of debris in circular electrode is higher than that in side-cut electrode. It can be seen that flushing of debris was increased when side-cut electrode was used. Simulation results reveal that side-cut electrode has a significant influence on debris exclusion from machin- ing zone, and hence it has exhibited better flushing characteristics as compared with circular electrode.

The reliability of developed model was validated based on Mass Flow Rate (MFR). For this purpose, several tests were conducted at varying drilling depths (at a range of 1$50 \mathrm{~mm}$ ) and inlet MFR values were measured. The corresponding outlet MFR values from models were compared with experimental values. Figure 15 shows that there is good agreement between experimental and numerical MFR values. CFD model has provided a linear correlation with coefficient of determination $\left(R^{2}\right)$ of 0.969 . This assures the reliability of developed model for accurate simulation of flow field through interelectrode gap.

\section{Conclusions}

In this research, circular and side-cut electrodes were used in hole drilling by EDD process. Several drilling operations were conducted for producing holes with different drilling times. Numerical models were developed for analysis of flushing capabilities. The results revealed that electrode shape has significant effects on machining performance as well as dimensional and surface characteristics of drilled holes. The main outcomes of this study are as follows:

- In aspect of machining performance, side-cut electrode provided higher MRR and EWR for all holes as compared with circular electrode. Similar trends of TWR were observed. The modifications on electrode geometry affected the erosion characteristics of both workpiece and electrode, leading to changes in material removal and electrode wear.

- For the assessment of dimensional features of drilled holes, deeper holes were obtained with side-cut electrode. Owing to the shape of side-cut electrode, spark intensity was increased at the bottom interelectrode gap, causing greater amount of material removal.

- Side-cut electrode also provided holes with lower OC. This is because of narrower contour along perimeter of side-cut electrode, leading to less amount of sidesparking which results in smaller enlargement on the diameter of drilled holes. 
- Regarding the surface quality of drilled holes, side-cut electrode provided lower SR values. Side-cut electrode has better flushing performance due to extra space at side interelectrode gap, allowing for easier removal of debris so that smoother hole surfaces were obtained.

- Numerical results also proved that side-cut electrode has improved flushing capabilities for efficient removal of air bubbles and eroded particles.

In spite of high electrode wear, the overall performance of side-cut electrode over circular electrode was superior due to improved erosion and flushing capabilities. Experimental and numerical results revealed that side-cut electrode is preferable for producing deep holes with good dimensional accuracy and improved surface quality.

Data availability. All the data used in this manuscript can be obtained by requesting from the corresponding author.

Competing interests. The authors declare that they have no conflict of interest.

Edited by: Xichun Luo

Reviewed by: Ali Al-Abadi and one anonymous referee

\section{References}

Bamberg, E. and Heamawatanachai, S.: Orbital electrode actuation to improve efficiency of drilling micro-holes by micro-EDM, J. Mater. Proc. Tech., 209, 1826-1834, 2009.

Bozdana, A. T. and Ulutas, T: The effectiveness of multi-channel electrodes on drilling blind holes on Inconel 718 by EDM process, Mater. Manuf. Process., 31, 504-513, 2016.

Dwivedi, A. P. and Choudhury, S. K.: Effect of tool rotation on MRR, TWR, and surface integrity of AISI-D3 steel using the rotary EDM process, Mater. Manuf. Process., 31, 1844-1852, 2016.

Fang, P. and Manglik, R. M.: The influence of inner cylinder rotation on laminar axial flows in eccentric annuli of drilling bore wells, Int. J. Transp. Phenom., 4, 257-274, 2002.

Hung, J. C., Lin, J. K., Yan, B. H., Liu, H. S., and Ho, P. H.: Using a helical micro-tool in micro-EDM combined with ultrasonic vibration for micro-hole machining, J. Micromech. Microeng., 16, 2705-2713, 2006.

Jahan, M. P., Wong, Y. S., and Rahman, M.: Evaluation of the effectiveness of low frequency workpiece vibration in deep-hole micro-EDM drilling of tungsten carbide, J. Manuf. Process., 14, 343-359, 2012.
Kong, W., Guo, C., and Zhu, X.: Simulation analysis of bubble motion under ultrasonic assisted electrical discharge machining, in: 3rd International Conference on Machinery, Materials and Information Technology Applications (ICMMITA), 28-29 November 2015, Qingdao, China, 2015.

Munz, M., Risto, M., and Haas, R.: Specifics of flushing in electrical discharge drilling, Proc. CIRP, 6, 83-88, 2013.

Nastasi, R. and Koshy, P.: Analysis and performance of slotted tools in electrical discharge drilling, Ann. CIRP: Manufact. Technol., 63, 205-208, 2014.

Plaza, S., Sanchez, J. A., Perez, E., Gil, R., Izquierdo, B., Ortega, N., and Pombo, I.: Experimental study on micro EDMdrilling of Ti6Al4V using helical electrode, Precis. Eng., 14, 821-827, 2014.

Selvarajan, L., Narayanan, C. S., and Jeyapaul, R.: Optimization of process parameters to improve form and orientation tolerances in EDM of MoSi2-SiC composites, Mater. Manuf. Process., 30, 954-960, 2015.

Selvarajan, L., Narayanan, C. S., and Jeyapaul, R.: Optimization of EDM parameters on machining Si3N4-TiN composite for improving circularity, cylindricity, and perpendicularity, Mater. Manuf. Process., 31, 405-412, 2016.

Shabgard, M. R. and Alenabi, H.: Ultrasonic assisted electrical discharge machining of Ti-6Al-4V alloy, Mater. Manuf. Process., 30, 991-1000, 2015.

Theory Guide: ANSYS FLUENT 12.0, Ansys Inc., 2009.

Wang, J. and Han, F.: Simulation model of debris and bubble movement in consecutive-pulse discharge of electrical discharge machining, Int. J. Mach. Tool. Manu., 77, 56-65, 2014a.

Wang, J. and Han, F.: Simulation model of debris and bubble movement in electrode jump of electrical discharge machining, Int. J. Adv. Manuf. Tech., 74, 591-598, 2014b.

Xie, B., Zhang, Y., Zhang, J., and Rend, S.: Numerical study of debris distribution in ultrasonic assisted EDM of hole array under different amplitude and frequency, Int. J. Hybrid Inf. Technol., 8, 151-158, 2015a.

Xie, B., Zhang, Y., Zhang, J., Dai, Y., and Liu, X.: Flow field simulation and experimental investigation of ultrasonic vibration assisted EDM holes array, Int. J. Control Autom., 8, 419-424, $2015 b$.

Yadav, U. S. and Yadava, V.: Experimental investigation on electrical discharge drilling of Ti-6Al-4V alloy, Mach. Sci. Technol., 19, 515-535, 2015.

Yahagi, Y., Koyano, T., Kunieda, M., and Yang, X.: Micro drilling EDM with high rotation speed of tool electrode using the electrostatic induction feeding method, Proc. CIRP, 1, 162-165, 2012.

Yu, Z. Y., Rajurkar, K. P., and Shen, H.: High aspect ratio microhole drilling aided with ultrasonic vibration and planetary movement of electrode by micro-ED M, Ann. CIRP: Manufact. Technol., 58, 213-216, 2009.

Zhang, W., Liu, Y., Zhang, S., Ma, F., Wang, P., and Yan, C.: Research on the gap flow simulation of debris removal process for small hole EDM machining with Ti alloy, in: 4th International Conference on Mechatronics, Materials, Chemistry and Computer Engineering (ICMMCCE), 12-13 December 2015, Xi' an, China, 2015. 